With regard to Captain Hutton's special instance, however, there appear to be certain points which require consideration before accepting the conclusion that the resemblance is merely a coincidence :-(1) The possible coexistence of the two species in other localities where the resemblance has a meaning; (2) the possible change of conditions in the struggle for life in the locality itself; (3) our possibly imperfect knowledge of the struggle which is waged there now. Furthermore, a careful comparison between both forms and their respective allies-a comparison which takes account of geographical distribution as well as of superficial appearance-would certainly throw light upon the origin of their present appearance, and probably upon the meaning of the likeness which they bear to each other.

When questions such as these have been answered so as to leave no doubt about the accidental nature of the resemblance, it will be necessary to ascertain whether the "offensive "qualities of the blow-fiy are any defence against insect-eating animals. If they are not, the resemblance would still lack an essential characteristic of true mimetic likeness.

Oxford, March 6.

E. B. Poulton.

\section{Area of Triangle in Terms of Sides.}

As the changes which are being introduced, in accordance with Prof. Perry's suggestions, into geometrical teaching are giving a stimulus to the production of text-books of practical geometry and mensuration, the present is a good time to point out a more direct proof of the formula for the area of a triangle in terms of its sides than that usually given.

From the centres of the inscribed and one escribed circle, drop perpendiculars on the sides or their productions. Also join these centres to the corners A, B, C.

We have then, by similar triangles,

$$
\frac{s-c}{r_{a}}=\frac{r}{s-b} \text {, whence } r r_{a}=(s-b)(s-c) \text {. }
$$

The area of the triangle $A B C$ is equal to $r s$, and also to $r_{a}(s-a)$; and therefore to $\left.\sqrt{ }^{\prime}{ }^{\prime} r_{a} s(s-a)\right\}^{\prime}$ that is to

$$
\sqrt{ }\{s(s-a)(s-b)(s-c) \text { ? }
$$

II Leopold Road, Ealing.

J. D. Everetr.

\section{LEONARDO DA VINCI AS A HYDRAULIC ENGINEER,}

$\mathrm{N}$ the December number of the Bulletin of the 1 French Society for the Encouragement of National Industry 1 is an article by $\mathbf{M}$. M. A. Ronna on Leonardo da Vinci, in his capacity of hydraulic engineer; with extracts from his works and several reproductions of sketches of the numerous mechanical contrivances he invented for saving labour, for measuring the discharge of water, for lock gates and other hydraulic appliances.

Leonardo da Vinci, who was born in Italy in $145^{2}$, has generally been recognised as one of the most illustrious painters of the world, being classed as an artist with Raphael and Michael Angelo. His most celebrated work was the fresco representing the Last Supper, which was painted in his middle life. He was also the author of a treatise on painting, which was published in several different languages. His gifts as sculptor, musician and poet are less known; and it may be a surprise to many to be told that Leonardo da Vinci was by profession an engineer, engaged principally in designing and carrying out works for the construction of canals, the drainage and reclamation of marshes, and similar work in Italy; and in his later life in France, to which country he was invited by Francis I. to advise as to hydraulic works there. He held the appointment of engineer and director of works in Lom-

1 Bulletin de la Société a" Encouragement pour. Industrie Nationale, December, 1902. (Paris: Published by the Society.) bardy and Tuscany, and also acted as chief engineer in the army of the Pope. In addition to his executive work, he thoroughly investigated the laws relating to the movement of water and hydraulics generally, and anticipated many of the theories for which credit is

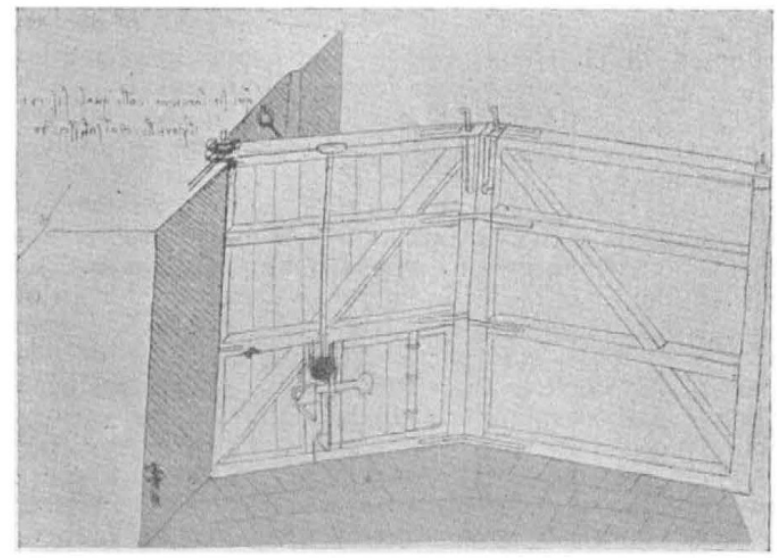

Fici. 1.

generally given to men of science who lived very many years later. He appears to have grasped a knowledge of the action of gravity more especially in its relation to the movement of liquids, and states his inability

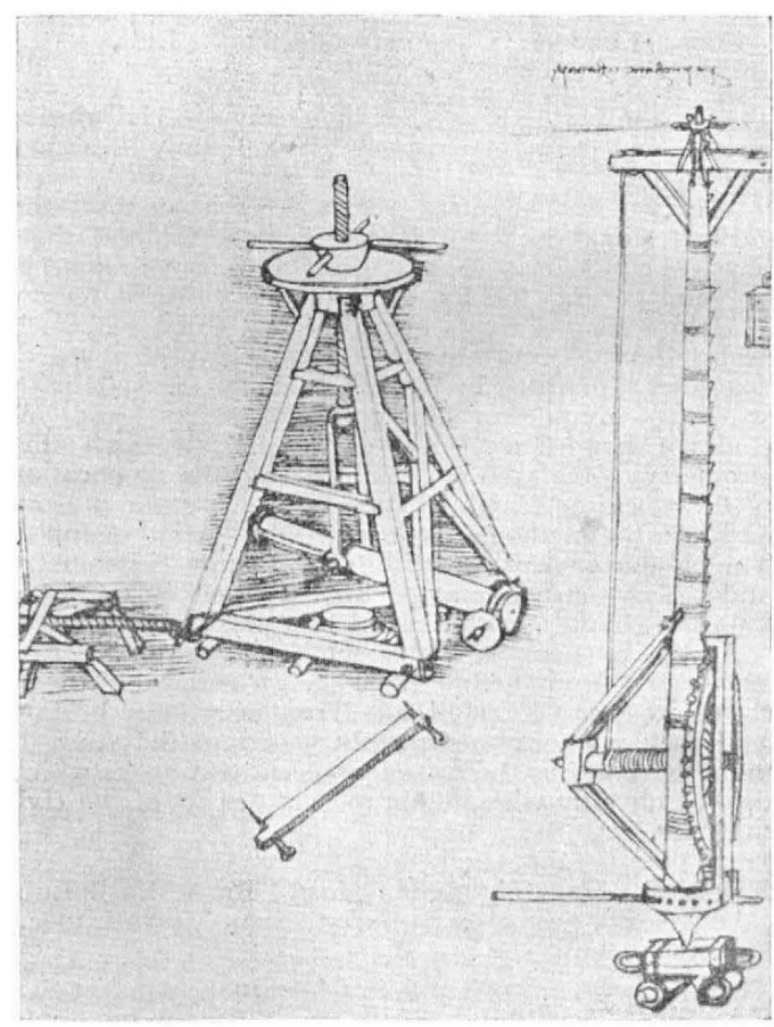

FIG. 2.

to furnish to the human mind a scientific proof of its existence, as he considered that, in common with magnetism and other phenomena, it was one of the secrets of Nature. Hallam, in his introduction to the 
"Literature of Europe," referring to Leonardo, says the discoveries which made the names of Galileo, Kepler, Castelli and others famous, the system of Copernicus, the very theories of recent geologists, were anticipated by da Vinci within the compass of a few pages, not perhaps in the most precise language, or in the most conclusive reasoning, but so as to strike in with something like the awe of preternatural knowledge.

Leonardo da Vinci in his writings deals with and explains the formation of rain drops, the capillary action of liquids, the equal pressure of water in closed vessels, anticipating the application of this principle as carried out nearly three centuries later by Bramah in his hydraulic press. The theory of the motion of waves in water is fully dealt with. The illustration he gives of a field of corn under the infiuence of the wind when a wave motion traverses the field without the stalks moving, to show the action of the water in similar circumstances, has been often used since, and was adopted by Scott Russell in his report to the British Association on waves in 1836 .

Leonardo da Vinci appears to have devoted much attention to the use of mechanical appliances for saving labour in the excavation and removal of earth in the various canals that he was engaged in constructing. He was the first engineer to adopt the use of weirs and locks for overcoming the varying levels of the country through which his canals were carried. A sketch of a pair of lock-gates (Fig. I), as used on the canal from Ticino to Milan, called the "Naviglio Grande," as given in his "Codicc Atlantico," is here reproduced. Gates of almost similar design may still be seen on many of the older canals of this country, where locks were not made use of until 1566. As specimens of the sketches of mechanical contrivances given in his treatise, the illustration of machinery for raising heavy weights (Fig. 2) bears a strong resemblance to appliances to be found amongst contractors' plant of the present day.

The theories set out by Leonardo da Vinci, and his laws for regulating the flow of water in open channels as derived from his own practice and observation, for ascertaining the velocity of discharge due to the balance of forces established between gravity and friction, as to the effect of the junction of two waterways, and the velocity of movement of water as affected by the form of the channel and the depth of the water, anticipated by fully a century the works of Gugliemini, of Paul Frisi and Castelli, to whom, generally, has been given the credit of first determining the problems of hydrology.

\section{THE PHYSIOLOGICAL LABORATORY OF THE UNIVERSITY OF LONDON.}

$\mathrm{T} \mathrm{T}$ was the fear of some of those most interested in 1 the renaissance of the University of London that the good effects of the transfer from Burlington House to the Imperial Institute would not become apparent until many years had clapsed. As scientific research is more and more taking its proper place as the highest duty that a university can perform, it is very gratifying to learn that the University of London has seized a favourable opportunity, and utilised its enlarged premises to this end. Even though this laudable endeavour must be at present regarded in the light of a preliminary experiment not yet included in any authorised programme, the physiological laboratory tentatively initiated by the University appears to be admirably adapted for the NO. 174 I, VOL. 67$]$ purposes to which it is applied, namely, for lectures on advanced physiology and for physiological research. But its chief value is as a concrete object-lesson of what the well-wishers of education in this country desire to see promoted by the University of London, and we are inclined to add, with bated breath, fed from the national exchequer. A municipal body may be expected to realise the importance of technical science, and to pay for its establishment. But it re-

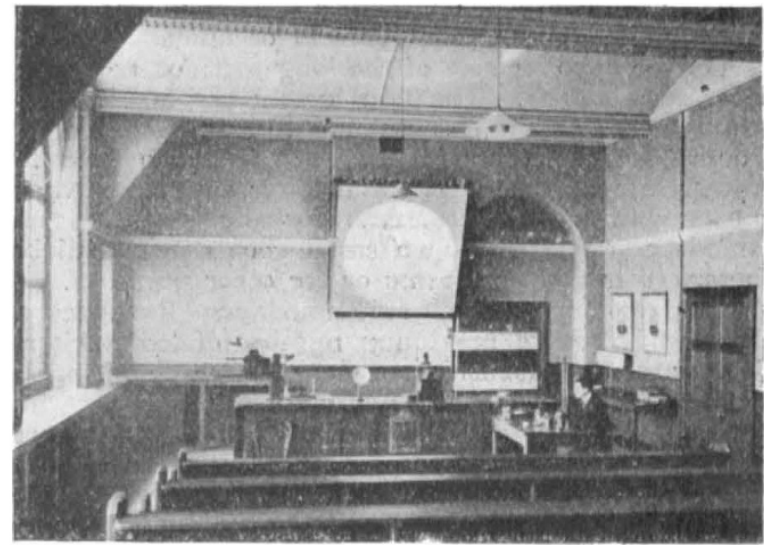

[FiG. x.-Room No. 17 (The I,ecture Room).

quires outlook towards a wider horizon to realise that apparently useless knowledge is in reality knowledge of which the reward is to be received by future generations.

The habitation of this infant laboratory at present comprises the top floor of one side of the main building. A long corridor extends throughout its whole length, and the various rooms open from this right and left. The first, counting from the entrance, is the workshop, where a I h.p. dynamo provides power for

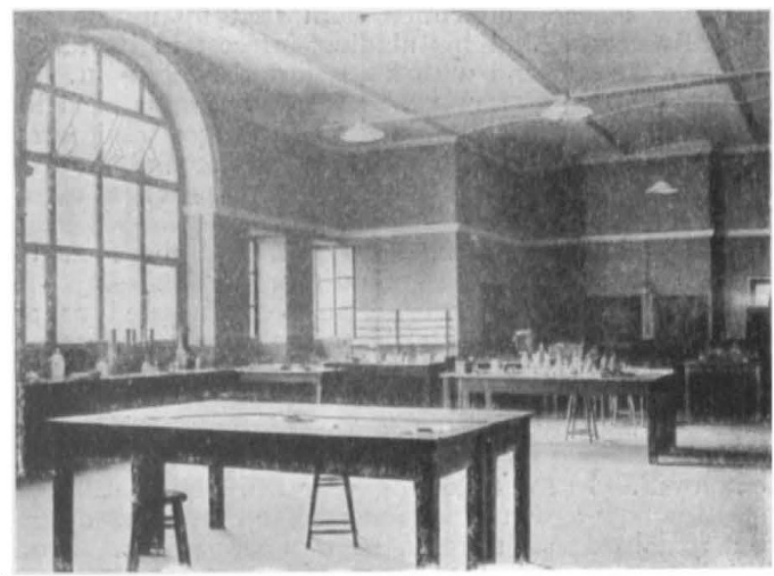

Fig. 2.-Room No. 19 (General Laboratory)

the various tools used in constructing the smaller apparatus required from time to time. Next is the lecture theatre, with seats for eighty students. Arranged for lectures in advanced physiology, this accommodation has so far proved sufficient; the average attendance has been about thirty, and as no attempt has been made to give merely popular demonstrations, and as only students are invited who already possess some knowledge of the subject, these numbers are very 